\title{
BENTUK KOREOGRAFI TORTOR ILAH MARDIDONG DI KABUPATEN SIMALUNGUN
}

\author{
KHELIANA \\ Prodi PendidikanTari
}

\begin{abstract}
Tor -tor dance IlahMardidong is growing and developing in Simalungun . Tor- tor dance is a tradition that has been rearranged forms of the movement in 1985 by a man named Lina Br Damanik . The purpose of this study is to discuss the tor-tor IlahMardidong viewed from the standpoint of choreographic form.

The theory used in this research is the theory of Forms choreography Sudarsono which contains about : motion, theme, design floors, top design, fashion and music. This theory became a reference for peeling the existing problems in the tor- tor god mardidong .

When the study to discuss IlahMardidong dance performed during 3 months ,ie from the beginning of October 2015 through December 2015. The study in the village of Huta III Glare Malela . Glare SubdistrictMalela. The population is three persons namely speakers, traditional leaders, and artists who know about the culture Simalungun . samples in this study were of three persons namely speakers , traditional leaders and artists in Simalungun. Data collection techniques including observation, interviews, literature study and documentation, which is then analyzed by qualitative descriptive method .

Based on research done that tor-tor IlahMardidong have a soft form of motion ,tortorIlahMardidong wear internal musical accompaniment is music that is born out of the human body. Clothing used in this Tortor is yeast pane ,surisuri and headdress silappei. The themes contained in this dance is the hope of a mother for her child, and the top design contained in this dance is the design in the design, low design and asymmetrical design .
\end{abstract}

Keywords : Shape, Choreography Tor - Tor IlahMardidong, Simalungun 


\section{PENDAHULUAN}

Sumatera Utara terdiri dari bermacam-macam suku diantaranya Batak Toba, Karo, Simalungun, Pakpak Dairi, Mandailing, Angkola, Pesisir Sibolga, Melayu dan Nias. Suku-suku tersebut adalah suku asli yang mendiami wilayah Sumatera Utara. Setiap suku memiliki ciri khas masing-masing, misalnya dalam hal adat istiadat, kesenian, bahasa, serta pakaian. Di Sumatera Utara terdapat berbagai macam kesenian tradisi, antara lain berupa tari tradisional dan musik tradisional.

Suku Simalungun merupakan salah satu rumpun Suku Batak, yang mendiami wilayah Kabupaten Simalungun Provinsi Sumatera Utara. Meskipun masyarakat Simalungun terbagi dua, berdasarkan wilayah Simalungun yaitu Simalungun atas (mulai dari daerah Siantar sampai Seribu Dolok) dan Simalungun bawah (mulai dari daerah Bandar sampai perbatasan Lima Puluh, tetapi mereka samasama terikat oleh sistem kekeluargaan yang sangat erat seperti dalam acara pesta adat dan aktivitas keseharian dan kesenian.
Kesenian merupakan suatu hasil karya manusi yang mempunyai keindahan dan dapat dinikmati serta dirasakan oleh manusia. Kesenian juga merupakan warisan yang tidak boleh dilupakan, melainkan harus dikembangkan karena dapat menjadi ciri khas dari suatu daerah tersebut. Kesenian biasa digunakan dalam ritual, upacara adat, hiburan, dan pertunjukan sehingga kesenian itu sendiri tidak lepas dari aktivitas masyarakat.

Tor-tor ilah mardidong merupakan tarian kreasi yang berpijak dari tradisi. Tor-tor ini telah ditata bentuk geraknya oleh seorang seniman Simalungun yang dari kecil nya telah menggeluti bidang seni baik di seni tari maupun seni tarik suara dikarenakan gerakkan asli pada tor-tor ini begitu sangat sederhana, sehingga terlihat begitu monoton. Oleh karena itu beliau membuat perubahan pada ragam geraknya yaitu pada gerakan tangannya saja, yang sebelumnya cuma menimangnimang kemudian dirubah menjadi lebih sedikit bervariasi namun tidak mengurangi unsur tradisinya. Hingga sekarang tor-tor Ilah Mardidong ini 
masih dipertunjukan di acara pesta adat masyarakat Simalungun, yaitu pesta Rondang Bintang yang diadakan sekali dalam setahun. Pada Tahun 2014 tor-tor ini ditampilkan di TMII dalam rangka Pargelaran Seni dan Budaya Simalungun yang diperankan sendiri oleh Lina Damanik.

Ilah mardidong terdiri dari dua kata, ilah yang berarti bernyanyi atau bersenandung dan didong yang bearti menimang atau mengayun. Tarian ini menceritakan tentang seorang ibu yang menidurkan anaknya terlebih dahulu sebelum memulai pekerjaan diladang, karena zaman dahulu pada umumnya di Simalungun pekerjaan laki-laki atau bapak-bapak adalah berburu kehutan, menangkap burung, membuat gula aren, mencari ikan atau memancing, sedangkan perempuan atau ibu-ibu bekerja ke ladang dan menjaga anak. Maka dari itu sebelum memulai pekerjaan sang ibu menidurkan anaknya terlebih dahulu diluar gubuk yang ada diladang dengan cara bernyanyi sambil menari agar pekerjaannya tidak terganggu, adapun rangkain dari tarian ini adalah menimang di tempat dengan kaki dienjut, menimang kedepan, menimang kebelakang, menimang ke samping kiri dan samping kanan. Gerakannya sangat simpel namun disetiap langkahnya mempunyai arti.

Tarian ini adalah tarian tunggal yang ditarikan oleh perempuan dengan menggunakan musik iringan internal (vocal)) berupa nyanyian yang berisikan lantunan nasihat-nasihat terhadap anak dengan menggunakan bahasa daerah setempat yaitu Simalungun. Berdasarkan pernyataandiatas, yang menjadi tujuan dalam penelitian ini adalah :"Mendeskripsikan Bentuk Koreografi Tor-tor Ilah Mardidong di Kabupaten Simalungun"

\section{Landasan Teori}

Untuk membahas bentuk koreografi tortor ilah mardidong penulis menggunakan teori bentuk koreografi dari Soedarsono.

\section{Lokasi dan Waktu Penelitian}

Tempatdilaksanakannyapenel itianadalah di Huta III SilauMalela Kecamatan Gunung Malela 
TeknikAnalisis Data

Penulis menganalisa dan
menguraikan data-data tersebut
dengan menggunakan teknik
kualitatif yaitu sebagai prosedur
pemecahan masalah yang diselidiki
dengan menggambarkan keadaaan
objek penelitian pada saat sekarang
Kabupaten Simalungun. Waktu yang
digunakan dalam penelitian ini untuk
mendapatkan data yang dibutuhkan
adalah selama tiga bulan yang akan
dilaksakan pada Oktober 2015
sampai Desember 2015.

\section{PopulasidanSampel}

\section{Populasi}

populasidalampenelitianinibe rjumlahtiga orang yaitunarasumber, tokohadat, danseniman.

\section{Sampel}

Sampel dalam penelitian ini berjumlah tiga orang yaitu nara sumber, tokoh adat dan seniman yang ada di Kabupaten Simalungun.

\section{Teknik Pengumpulan Data}

Teknik pengumpulan data yang dilakukan adalah sebagai berikut:
1. Studi kepustakaan

2. Observasi

3. Wawancara

4. Dokumentasi

ISI

Kabupaten Simalungun adalah salah satu kabupaten yang terdapat di propinsi Sumatera Utara. Kabupaten Simalungun terdiridari 31 kecamatan, 350 kelurahan dengan jumlah penduduk ditahun 2015, sekitar 844.033 jiwa.

Suatu unsur budaya yang tidak pernah hilang dikalangan masyarakat Simalungun adalah kesenian, yang hampir tidak pernah mengalami kemandekan bahkan cenderung berkembang. Masyarakat Simalungun melakukan aktivitasaktivitas yang berkaitan dengan kehidupan sehari-hari dengan menyertakan keseniaan sebagai kelengkapan pelaksanaan kegiatan. Selain untuk hiburan dan rekreasi, bentuk-bentuk kesenian ini mempunyai fungsi ritual, pendidikan, penerangan, sekaligus sebagai sarana untuk mempertahankan keseimbangan dan struktur social 
masyarakat. Di samping itu ada pula bentuk kesenian Seperti: Tor-tor Sombah,Tor-tor Harouan Bolon, Tor- tor Manduda, Tor-tor Sitalasari, Tor-tor Toping-toping/Huda, Ilah, seni musik, dan senirupa. Yang juga tidak terlupakan dari masa kemasa, Karena orang Simalungun kaya akan seni budaya.

\section{Tortor Ilah Mardidong di} Kabupaten Simalungun

\section{Tor-torilah mardidong} merupakan tarian kreasi yang berpijak dari tradisi. Tor-tor ini telah ditata ulang bentuk geraknya oleh seorang seniman Simalungun yang dari kecil nya telah menggeluti bidang seni baik di seni tari maupun seni tarik suara dikarenakan gerakkan asli pada tor-tor ini begitu sangat sederhana, sehingga terlihat begitu monoton. Oleh karena itu beliau membuat perubahan pada ragam geraknya yaitu pada gerakan tangannya saja, yang sebelumnya cuma menimang-nimang kemudian dirubah menjadi lebih sedikit bervariasi namun tidak mengurangi unsur tradisinya. Hingga sekarang tor-tor Ilah Mardidong ini masih dipertunjukan di acara pesta adat masyarakat Simalungun, yaitu pesta Rondang Bintang yang diadakan sekali dalam setahun. Pada Tahun
2014 tor-tor ini ditampilkan di TMII dalam rangka Pargelaran Seni dan Budaya Simalungun yang diperankan sendiri oleh Lina Damanik.

Ilah mardidong terdiri dari dua kata, ilah yang berarti bernyanyi atau bersenandung dan didong yang bearti menimang atau mengayun. Tarian ini menceritakan tentang seorang ibu yang menidurkan anaknya terlebih dahulu sebelum memulai pekerjaan diladang, karena zaman dahulu pada umumnya di Simalungun pekerjaan laki-laki atau bapak-bapak adalah berburu kehutan, menangkap burung, membuat gula aren, mencari ikan atau memancing, sedangkan perempuan atau ibu-ibu bekerja ke ladang dan menjaga anak. Maka dari itu sebelum memulai pekerjaan sang ibu menidurkan anaknya terlebih dahulu diluar gubuk yang ada diladang dengan cara bernyanyi sambil menari agar pekerjaannya tidak terganggu, adapun rangkain dari tarian ini adalah menimang di tempat dengan kaki dienjut, menimang kedepan, menimang kebelakang, menimang ke samping kiri dan samping kanan. Gerakannya sangat simpel namun disetiap langkahnya mempunyai arti.

Adapun ragam gerak tari dalam tortor ilah mardidong ini yaitu intro masuk, mardidong hianan (menimangditempat), mardalan hulobei (berjalankedepan), mardalan 
hupudi (berjalan kebelakang), mardalan husiamun (berjalan kesamping kanan), mardalan sambilo (berjalan kesamping kiri), mesimpuh (bersimpuh).

Gambar ragam gerak tortor ilah mardidong:

a. Intro Masuk

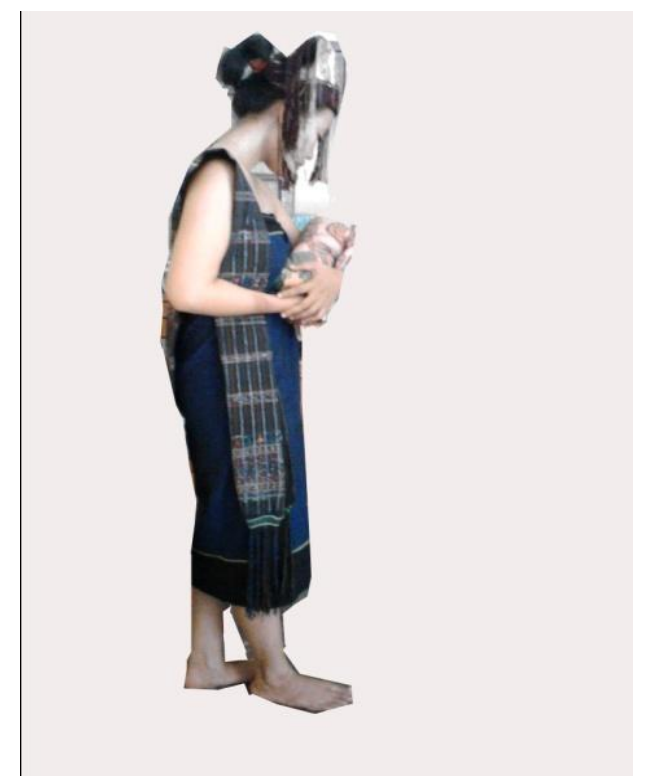

b. Mardido

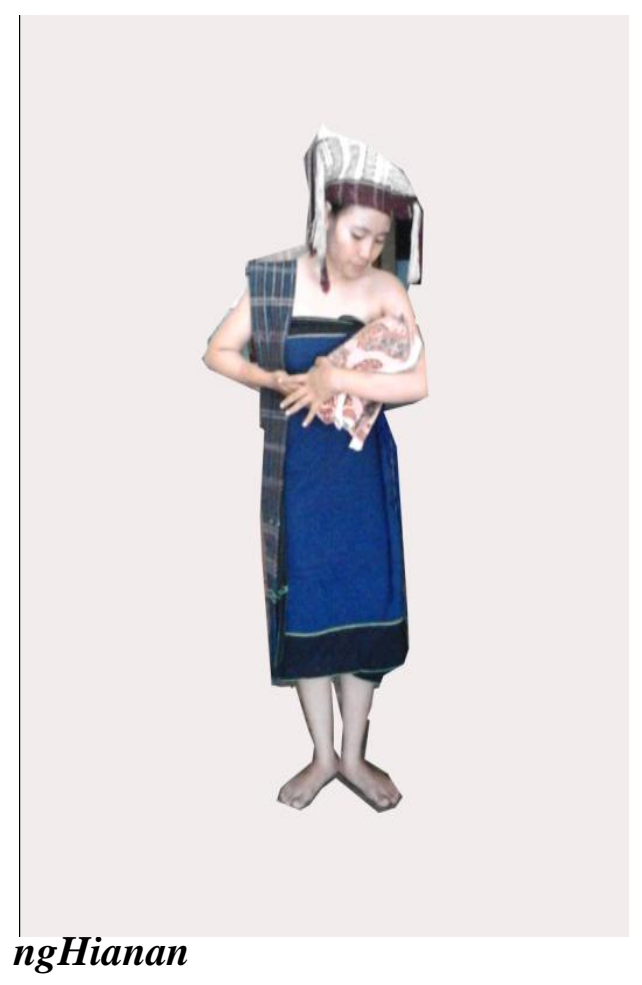

c. Mardalan Hulobei

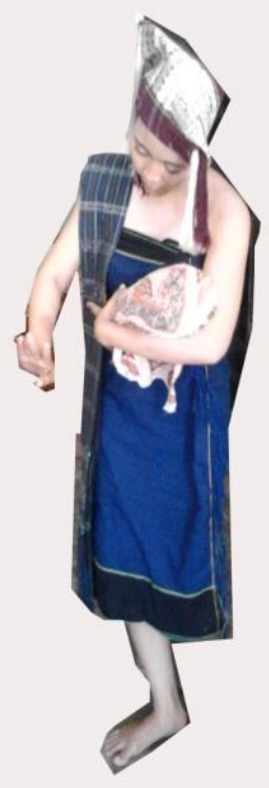


d. MardalanHupudi

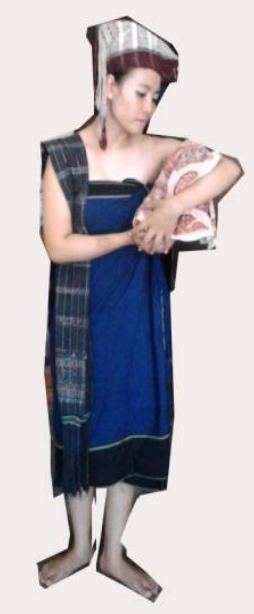

e. Mardalan Husiamun

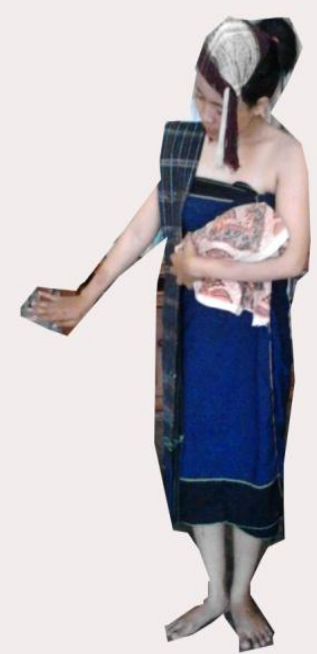

\section{f. Mardalan Sambilo}

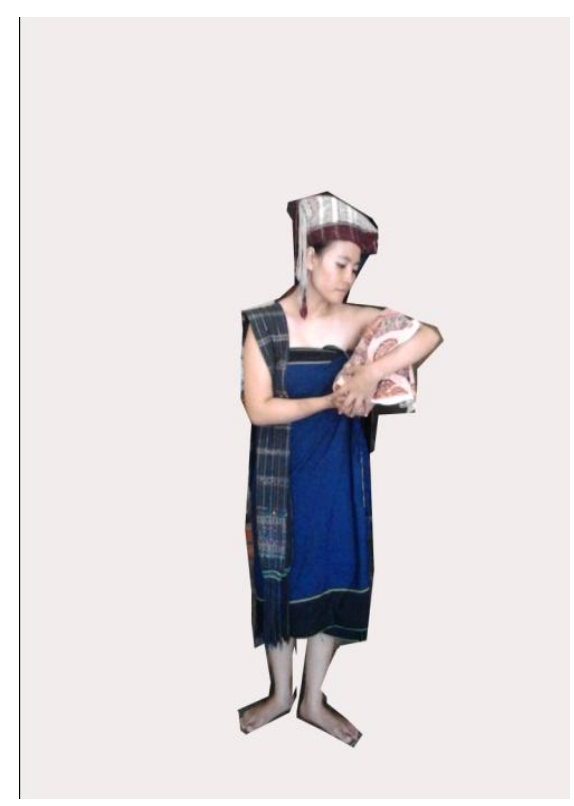

g. Mesimpuh

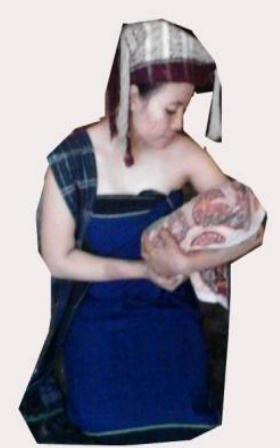




\section{PENUTUP}

\section{Kesimpulan}

Dari hasil penelitian yang dilakukan di lapangan dan penejelasan yang sudah di uraikan mulai dari latar belakang hingga pembahasan, maka dapat disimpulkan secara keseluruhan terhadap Tor-tor Ilah Mardogei di Huta III Silau Malela Kabupaten Simalungun sebagai berikut :

1. Tarian ini menceritakan tentang seorang ibu yang menidurkan anaknya terlebih dahulu sebelum memulai pekerjaan diladang, karena dahulu kala pada umumnya di Simalungun pekerjaan laki-laki atau bapakbapak adalah berburu kehutan, menangkap burung, membuat gula aren, mencari ikan atau memancing, sedangkan perempuan atau ibu-ibu bekerja ke ladang dan menjaga anak. Maka dari itu sebelum memulai pekerjaan sang ibu menidurkan anaknya terlebih dahulu diluar gubuk yang ada diladang dengan cara bernyanyi sambil menari agar pekerjaannya tidak terganggu, adapun rangkain dari tarian ini adalah menimang di tempat dengan kaki dienjut, menimang kedepan, menimang kebelakang, menimang ke samping kiri dan samping kanan. Gerakannya sangat simpel namun disetiap langkahnya mempunyai arti.

2. Musik iringan pada Tor-tor Ilah Mardidong merupakan musik internal yang berasal dari dalam tubuh penari.

3. Tema yang terdapat dalam tari Ilah Mardidong merupakan harapan seorang ibu terhadap 
anaknya yaitu, agar kelak

tumbuh dewasa kesuksesan

menyertai anaknya dan setelah

sukses jangan lupa diri dan

lihatlah sekeliling bantu saudara-

saudara yang membutuhkan

pertolongan. Dari penjelasan

diatas, dapat disimpulkan bahwa

melalui tor-tor Ilah Mardidong

ini menjadikan manusia yang

bersosialitas tinggi terhadap

sesama.

4. Pada tor-tor ilah mardidong ini geraknya sangat lembut dan terdapat beberapa ragam gerak diantaranya adalah mardidong hianan, mardalan hulobei, mardalan hupudi, mardalan sambilo, mardalan husiamun dan mesimpuh.

5. Busana yang digunakan penari pada Tor-tor Ilah
Mardogei adalah ragi pane, dan suri-suri.

6. Desain lantai pada tor-tor ilah mardidong yaitu lurus kedepan, lurus kebelakang, serta lurus kesamping kiri dan kanan.

7. Desain atas yang terdapat pada tor-tor ilah mardidong ini yaitu desain dalam, desain rendah dan asimetris.

\section{Saran}

Dari hasil kesimpulan penelitian diatas, maka dapat diajikan beberpa saran antara lain sebagai berikut :

1. Penulis berharap dengan adanya peneltian ini masyarakat Simalungun untuk menjaga , mengembangkan serta melestarikan tari-tarian yang berada pada masyarakat 
Simalungun khususnya di Kabupaten Simalungun

2. Diharapkan kepada masyarakat Simalungunkhususnya kepada pemerintah daerah agar senantiasa memperkenalkan berbagai tari-tarian kepada masyarakat luas baik lokal maupun diluar daerah dan mengadakan pertunjukkan kesenian Simalungun agar dapat memahami keseniaan Simalungun baik secara bentuk geraknya hingga makna yang ingin disampaikan akan tersampaikan kepada penikmat seni maupun masyarakat yang menyaksikanya.

3. Dengan meningkatkan kepedulian terhadap kesenian daerah, berarti telah menyelamatkan anak cucu kita dari pengaruh budaya luar yang akan merusak budaya sendiri. Semoga penelitian ini dapat memberikan pengetahuan baru bagi masyarakat Simalungunbagaiman bentuk koreografi tari Simalungun 


\section{DAFTAR PUSTAKA}

Angelia, Yere. 2012 "Bentuk Koreografi Tor-Tor Dihar sitarlak di Kabupaten Simalungun" Skripsi. Universitas Negeri Medan.

Ali, Muhammad. 2002. Penelitian Kependidikan dan Prosedur Strategi.Bandung Angkasa.

Botomi, Irma. 2013 “Tor-Tor Sirintik pada Masyarakat Simalungun, Kajian Terhadap Bentuk Koreografi" Skripsi.UniversitasNegeri Medan.

Maryeni, 2005.Metode Penelitian Kebudayaan. Jakarta: BumiAksara

Mulgiyanto, Sal. 1986. Koreografi Tari (Pengetahuan Elementer Taridan Beberapa Masalah Tari).

Nasution, AfniDayanti. 2014 "Makna Teks Tari Ilah Bolon dalam Upacara Rondang Bintang”.UniversitasNegeri Medan.

Nazir, Mohammad. 1988. MetodePenelitian, Gahlia Indonesia: Jakarta.

Nurwani, 2014. "bahan Ajar PengetahuanTari" Unimed Press: Medan

SaragihSt.J.E. 1989. "KamusSimalungun Indonesia" PematangSiantar

Sakri, A. 1990 "Pendidikan Seni Rupa” Depdikbud: Jakarta
Seriati, Ni Nyoman. 2008, "Komposisi dan Koreografi" Yogyakarta

Sitanggang, Radesman. 2014. "Orientasi Nilai Budaya Folklore Etnik Simalungun" L-SAPA: Pemantang Siantar

Soedarsono, 1986, "Elemen-Elemen Dasar Komposisi Tari” Yogyakarta Yuningtyas, $\quad$ Risty. 2014 "Perkembangan Pesta Rondang Bintang Pada Masyarakat Simalungun".Universitas Negeri Medan. 
Gesture 